\title{
Habitar várias línguas: \\ a escrita multiterritorializada \\ de Najat el Hachmi
}

Ana Beatriz Rodrigues Gonçalves Recebido em 17 jul 2012 - Aprovado em 18 set 2012

\section{Resumo}

O objetivo deste trabalho é, através da leitura de Jo també soc catalana (2004) de Najat Najat El Hachmi, imigrante marroquina radicada em Barcelona, Espanha, pensar as formas com as quais a escritora vive o que Rogério Haesbaert denomina multiterritorialidade. Observaremos como através da experiência de habitar várias línguas, o amazigh, o catalão e o castelhano, a autora reforça a ideia de identidade híbrida.

Palavras-chave: multiterritório; identidade híbrida; Najat El Hachmi. 
1 No original: "si los españoles olvidan que también ellos fueron inmigrantes en el extranjero, es porque la inmigración no constituye motivo de orgullo para nadie. Incluso en ocasiones es motivo de vergüenza. Evoca la miseria, el hambre, la dureza de las relaciones entre españoles, en su propia tierra... Resulta una especie de fracaso histórico". Tradução nossa. Todas as traduções no texto são de nossa autoria.
Propomos através da leitura de Jo també soc catalana (2004) de Najat Najat El Hachmi, imigrante marroquina radicada em Barcelona, observar as formas com as quais a escritora vive a multiterritorialidade, segundo a concepção de Rogério Haesbaert. Observaremos como ao habitar várias línguas, o amazigh, o catalão e o castelhano, a autora desarticula a ideia de um linguajamento nacional.

A imigração na Espanha é um fenômeno recente. Historicamente um país de emigrantes, só a partir de 1973, com a crise do petróleo a tendência emigratória espanhola diminuiu. A Espanha se tornou um país mais atraente depois de sua entrada na União Europeia (1986), quando recebeu grande quantidade de recursos para reformar o país que acabara de sair de uma das maiores ditaduras europeias com o general Francisco Franco. A ajuda econômica do bloco europeu fez com que deixasse de ser um país atrasado e essencialmente rural e passasse a industrializado, de primeiro mundo. Mesmo assim, até a década de 1980 havia mais emigrantes espanhóis que imigrantes chegando à Espanha. Entretanto, no período de 1991 a 2001 a população estrangeira residente legalmente na Espanha quase triplicou, passando de aproximadamente 360 mil para mais de um milhão de indivíduos. Para a Espanha, essa reversão do ciclo emigratório para o imigratório implica desafios: um país que já se mostrou pouco capaz de conviver com a pluralidade interna, deve agora enfrentar a convivência com pessoas de outras crenças, etnias, línguas e culturas.

Apesar de, então, a Espanha por muito tempo ter sido vista como um país de emigrantes, este fato parece que atualmente foi esquecido pelos espanhóis que rechaçam os imigrantes dentro do país. Para Sami Naïr:

se os espanhóis esquecem que também eles foram imigrantes no estrangeiro, é porque a imigração não constitui motivo de orgulho para ninguém. Inclusive em ocasiões é motivo de vergonha. Evoca a miséria, a fome, a dureza das relações entre os espanhóis na sua própria terra... Resulta numa espécie de fracasso histórico. (NAÏR, 2010, p.100) ${ }^{1}$

Dentro desse contexto de migrações, a região da Catalunha, sobretudo a cidade de Barcelona, vem há algumas décadas, atraindo tanto migrantes originários de outras regiões espanholas quanto imigrantes de outros países, principalmente o Marrocos. Esta região é escolhida por seu alto padrão de desenvolvimento dentro da península ibérica, com grandes investimentos principalmente na área da construção civil.

A imigração implica um deslocamento de pessoas no espaço e, seja esse espaço físico, social, econômico, político e/ou cultural. A imigração pode também ser considerada uma provação para a suposta "ordem nacional", uma tentativa social e política, também 
conservadora de manutenção de um status quo que não se quer abalado.

Segundo Abdelmalek Sayad (1998),

na medida em que os contatos do imigrante com a sociedade que o agrega a si se prolongam, se ampliam e se intensificam, ou seja, na medida em que o imigrante sai da esfera em que o restringem tradicionalmente o estatuto e a condição que lhe são atribuídos, na medida em que vai ganhando novos espaços (alguns deles inéditos, como o espaço político), chegando a desmentir a definição dominante que se dá dele e da imigração, indo até o questionamento da representação que se tem dele e que ele tem de si mesmo, o tratamento social e o tratamento científico, sendo que este encontra-se com frequência na dependência daquele, reservados ao imigrante e, mais amplamente, a todo o fenômeno da imigração, ganham em extensão e em compreensão. (SAYDAD, 1998, p.14)

Considerando as reflexões de Sayad, tomamos como ponto de partida as seguintes questões: o que os textos "falam" sobre a experiência da imigração? Como se posiciona o sujeito? Como "habita" outras línguas? Como vive as multiterritorialidades, sejam elas físicas, sociais, culturais, linguísticas?

Rogério Haesbaert em $O$ Mito da Desterritorialização (2004) propõe o conceito de multiterritorialidade que, segundo o autor, "é a forma dominante, contemporânea ou 'pósmoderna' da desterritorialização, a que muitos autores, equivocadamente, denominam desterritorialização" (2004, p. 338), uma vez que, seguindo o pensamento de Milton Santos (1996), desterritorialização implica estranhamento, desculturização. Argumenta, com Deleuze e Guattari, que toda desterritorialização requer uma forma de re-territorialização, isto é, a reconstrução do território em novas bases.

Haesbaert defende que a multiterritorialidade está relacionada com a experiência de vários territórios ao mesmo tempo e, a partir daí, a formulação de uma territorialização múltipla. Fica evidente a necessidade de se pensar o território "a partir de uma concepção de espaço como um híbrido - híbrido entre sociedade e natureza, entre política, economia e cultura, entre materialidade e 'idealidade'"' (HAESBAERT: 2004, p. 79). Território seria, então, concebido "a partir da imbricação de múltiplas relações de poder, do poder mais material das relações econômico-políticas ao poder mais simbólico das relações de ordem mais estritamente cultural" (HAESBAERT: 2004, p. 79).

O conceito de "território", porém, sugere um diálogo junto aos conceitos de "espaço" e "lugar". Doreen Massey, em Space, place and gender (1994), contesta a compreensão do espaço como algo estático, defendendo a definição de espaço de forma integradora com o tempo, como configuração de relações sociais. Assim, devido ao fato de as relações sociais estarem embutidas com questões 
2 No original: "For, as with space, so with place certain formulations of the concept are embedded in connotations of linked and interplaying dichotomies which in turn are related [...] to gender. In the pair space/place it is place which represents Being, and to it are attached a range of epithets and connotations: local, specific, concrete, descriptive. [...] The contrary to these classically designated characteristics of place are terms such as: general, universal/ theoretical/abstract/ conceptual".

3 No original: "Home is a multidimensional and profoundly symbolic term that cannot be mapped as an exclusively spatial concept, but it can be depicted as one aspect of human emotional territory."

4 No original: "Individual regions of home are constantly being constructed and deconstructed." de poder, significado e simbolismo, o conceito de espaço passa a implicar uma multiplicidade de espaços simultâneos. Paralelo às posições de espaço, Massey observa que o conceito de lugar também é caracterizado por sua limitação e identidade fixa. A proposta da autora consiste em pensar o espaço a fim de repensar as conceituações de lugar, uma vez que estes elementos coexistem no modo de pensamento dualístico do Ocidente:

Há, como com espaço, tanto quanto com lugar determinadas formulações do conceito que estão embutidas nas concatenações de dicotomias relacionadas e interagidas que de alguma forma estão vinculadas [...] com o gênero. No par espaço/lugar é o lugar que representa o Ser, e que está anexado a uma gama de epítetos e conotações: local, específico, concreto, descritivo. [...] O contrário dessas características de lugar classicamente nomeadas são termos como: geral, universal, teórico/abstrato/ conceitual. (MASSEY, 2009, p. 9)².

O território, para Haesbaert "não é simplesmente uma 'coisa' que se possui ou uma forma que se constrói, mas, sobretudo uma relação social mediada e moldada na/pela materialidade do espaço" (HAESBAERT, 2009, p. 350). A circunstância análoga do espaço com o território está na maneira como o espaço é "funcionalizado" através das relações sociais, constituindo o território. O espaço, portanto, não deve ser interpretado como algo incapaz de movimentar-se.

Theano Terkenli (1996) afirma que "lugar é um termo simbólico multidimensional e profundo que não pode ser mapeado como um conceito exclusivamente espacial, mas pode ser percebido como um aspecto do território emocional humano" (p. 327) ${ }^{3}$. Por esse motivo, ainda segundo o autor, "as regiões individuais de lugar são constantemente construídas e desconstruídas" (p. 327) ${ }^{4}$. Lugar é também uma expressão da identidade pessoal ou de um grupo demonstrando, assim uma necessidade de um ponto de referência, de identificação do EU ou de um grupo com esse espaço (aqui em um sentido amplo). Por isso mesmo, as geografias do lugar estão intimamente relacionadas aos modos de interação com esse lugar.

Dito isso, passemos a algumas considerações sobre nossa autora. Najat El Hachmi, de origem berbere (um conjunto de povos do Norte de África que falam línguas berberese e que chamam a si próprios imazighen, ou seja, "homens livres", singular amazigh), nasceu no Marrocos no ano de 1979 e aos oito anos de idade passa a morar na Catalunha, lugar para onde seu pai já havia emigrado. Em Barcelona, El Hachmi licencia-se em Filologia Árabe pela Universidade de Barcelona, com especial interesse na língua amazigh. Suas obras, Jo també sóc catalana publicada em 2004, ensaio declaradamente autobiográfico no qual trata da questão da integração dos imigrantes na Catalunha. A segunda, L'últim patriarca, de 2008, traduzida ao espanhol com o título El último patriarca. O romance 
5 No original: "la autora hace um recorrido por su experiência vital como catalana com uma cultura familiar no mayoritaria a través de cinco capítulos: reflexiona sobre la experiência de vivir en varias lenguas simultáneamente y los conflitos sobrevenidos: nos descubre su vida entre dos mundos sin cabida plena en ninguno; retrata el rechazo xenófobo hacia la cultura musulmana a través de justificaciones religiosas; nos devuelve el paternalismo occidental que aliena la mujer musulmana con argumentos aparentemente feministas; $y$ por último nos comunica la pérdida del mundo que dejó atrás todo inmigrante sin posibilidad de retorno"

6 No original: "esglaó intermedi, formo part del que jo anomenaria generació de frontera, altrament mal dita $<<$ segona generació $>>$." mostra a história de um imigrante marroquino que se instala na Catalunha, um patriarca onipotente, déspota às vezes, que se vê confrontado com as mudanças culturais da sua filha, que rompe com as tradições marroquinas e se adapta aos valores da nova sociedade. Essa obra ganha o prestigioso prêmio Ramon Llull em 2008. E por fim La caçadora de cossos, (traduzido ao espanhol como La cazadora de cuerpos), publicado em 2011, um romance que foge da temática das duas obras anteriores por não tratar da questão do viver entre dois mundos, do choque de culturas, mas sim tratar de questões mais existencialistas ao narrar a história de uma mulher que, faminta por aprendizado e exploração do desconhecido, acumula experiências sexuais em prol de saciar sua sede de felicidade e seus vazios emocionais.

Em Jo també soc catalana (2004)

a autora faz um percurso por sua experiência vital como catalã com uma cultura familiar não majoritária através de cinco capítulos: reflete sobre a experiência de viver em várias línguas simultaneamente e o conflitos resultantes: nos mostra sua vida entre dois mundos sem caber plenamente em nenhum; retrata a rejeição xenófoba à cultura muçulmana através de justificativas religiosas; nos devolve o paternalismo ocidental que aliena a mulher muçulmana com argumentos aparentemente feministas; e por último nos comunica a perda do mundo que todo imigrante sem possibilidade de retorno deixa. (CELAYA-CARRILLO: 2011, p. 347) $)^{5}$.

O texto nos mostra três formações culturais em disputa: espanhola, catalã e marroquina. O nacionalismo catalão é o que mais sobressai, o que ocupa maior espaço e influência.

Com Walter Mignolo, constatamos como os movimentos migratórios estão desarticulando a ideia do linguajamento nacional, estilo de vida entre línguas implica um processo de transformação social. Observamos um "desatamento do laço 'natural' entre línguas e nações, línguas e memórias nacionais, línguas e literatura nacional" (MIGNOLO, 2003, p. 396).

Para nossos propósitos nos ateremos principalmente à primeira parte do livro, "Les llengües maternes" (As línguas maternas), por tratar-se, como dito anteriormente, de uma reflexão sobre habitar várias línguas, sobre o linguajamento, na concepção de Mignolo. Interessa-nos observar como El Hachmi mobiliza recursos de uma língua, o catalão, para expressar suas experiências como imigrante. Como produz, a partir de uma perspectiva subalterna, uma nova posição discursiva.

Já no prólogo, observamos a rejeição ao que alguns denominam segunda geração de imigrantes para defini-la e a sua geração. El Hachmi se considera "escalão intermediário, faço parte do que eu chamaria geração de fronteira, de outro modo mal chamada 'segunda geração'" (EL HACHMI, 2004, p.13) ${ }^{6}$. O termo geração de fronteira, é, para a autora, mais adequado para denominar os 
herdeiros de projetos paternos que não pensam como seus pais e não se encaixam totalmente no pensamento autóctone.

O primeiro capítulo do livro, "Les llengües maternes" ("As línguas maternas"), trata especificamente da sua relação com as duas línguas com as quais se identifica: o catalão e o amazigh.

El Hachmi se mostra consciente da importância do conhecimento da língua do país de acolhida para chegar-se a entender o mundo novo que a imigração expõe aos imigrantes, um mundo novo com novas paisagens e novas ideias, novas pessoas: "A língua era uma necessidade vital ... entender o catalão era abrir as portas a um novo mundo, ter a chave para aceder à intimidade dos habitantes daquele país de neblina". (EL HACHMI, 2004, p.38) ${ }^{7}$

O grau de identificação com o catalão é tão grande que ela afirma que, quando ainda adolescente, já se via pensando nesta língua e não em amazigh, como os colegas: "Todos pensavam na sua língua materna. Eu era a exceção". (EL HACHMI, 2004, p.47) ${ }^{8}$ Perceber que seu discurso interno era em catalão confirma "as minhas suspeitas que já não era a mesma pessoa que tinha chegado aquele lugar do mundo" (EL HACHMI, 2004, p.47), o que reforça nosso argumento de multiterritorialização sócio-cultural.

Observamos no texto algumas formas de como o nacionalismo catalão institucionalizado nega ao imigrante o direito de considerar-se catalão e como o espanhol marca o "estrangeiro", o "estranho". Com Mignolo (2003) lemos que "a fala e a escrita são estratégias para orientar e manipular os domínios sociais de interação" (MIGNOLO, 2003, p. 309). Assim, o uso do castelhano a coloca no lugar do "outro", do estrangeiro, do imigrante indesejado:

Quando alguém diz que te integres, o que em realidade está pedindo é que te desintegres, que borres qualquer rastro de tempos anteriores, de vestígios culturais ou religiosos, que esqueças tudo e não recordes mais as suas recordações, o seu passado (EL HACHMI: 2004 p. 90) ${ }^{9}$.

Em um episódio em uma loja, Najat nos conta como a dona

7 No original: “La llengua era una necessitat vital, (...) entendre el català era obrir-se les portes a un nou món, tenir les claus per accedir a la intimitat dels habitants d'aquell país de boira"

8 No original: "Tots pensaven em la seva llengua materna. Jo era l'excepció"

9 No original: "obrir-se las portes a um nou mon, tenir les claus per accedir a la intimitat dels habitants d'aquell país de boira" fala com ela e com seu filho em espanhol, ao mesmo tempo em
que fala com os funcionários em catalão (p. 51). A esse episódio ela responde que "quase todos os marroquinos dessa idade falam a sua língua perfeitamente, é a língua da escola" (EL HACHMI, 2004, p.51). Segue o texto com a seguinte reflexão:

Não sei bem por que alguns catalães se ofendem se falamos na sua língua... ou é que no fundo toda aquela gente que responde sempre em castelhano, continua pensando como falantes de língua minoritária? (EL HACHMI, 2004, p. 52).

Esta concepção política e social catalã que El Hachmi reflete se deve ao caso concreto catalão. Sobretudo no período democrático, pós Franco, a historiografia catalã está marcada por conflitos nacionalistas que opõem a Catalunha contra o resto da Espanha, 
${ }^{10}$ No original: “Um país que era el meu, que já havia après a estimar-me com qualsevol altre catalã"

11 No original: "ni tan sols és la llengua dels teu pares, és la llengua dels opressors en un regneon l'amazic sempre s'ha considerat de segona categoria, llenguatge oral, només, bàrbars, ens diuen... La teva altra llengua maternal, el català, fou en alters temps perseguida I neystinguda, no en va la teva mare les sent com dues lengües germanes". principalmente contra o centro político representado por Castela e Madri, com o objetivo de reforçar a legitimação do governo local e as aspirações catalãs. A grande tarefa era nacionalizar o povo catalão que, seguindo a política de Jordi Pujol, presidente da comunidade autônoma (Generalitat de Catalunha) pela primeira vez em 24 de abril de 1980, sendo reeleito consecutivamente em 1984, 1988, 1992, 1995 e 1999 consistia no ensino da história catalã nas escolas para que "los catalanes entiendan lo que son y no otra cosa” (CELAYA-CARRILO, 2011, p.349).

A percepção que tem El Hachmi da língua catalã como mecanismo de pertencimento está relacionada à política de Pujol de conectar língua e identidade étnica. Assim, é possível essa identificação com o projeto nacionalista. Entretanto, percebemos uma intensificação da relação de língua a classe social: o estrangeiro (o outro), o indesejado não se encaixa no projeto sócio-linguístico catalão.

Mas, apesar de às vezes questionar a validade do discurso nacionalista da causa catalã, identifica-se com ele. $\mathrm{O}$ fato de optar por uma língua "minoritária", o catalão, indica uma posição ideológica. Com um companheiro de classe, Jordi, mantém uma aliança "nacionalista". Ao falar em catalão divide com ele o ideal de uma nação livre. Ao contrário dos demais colegas que rejeitam essa postura e defendem claramente o discurso nacionalista espanhol ao pedir que ela "hable en cristiano" (falar em cristão, ou seja, falar em castelhano) ou quando afirmam que Catalunha não é um país, mas uma comunidade autônoma. Mas para ela, entender o catalão significa "abrir as portas a um novo mundo, ter as chaves para aceder à intimidade dos habitantes daquele país de neblina" (EL HACHMI, 2004, p. 38). Assim, temos que a percepção de El Hachmi em relação à língua catalã como modo de pertencimento tem, também, um significado político, paralelo ao desenvolvido por Pujol. Uma tentativa de redefinir uma conexão entre língua e identidade étnica. Constata-se, então, um vínculo afetivo, resultado de suas experiências, parte do seu processo de formação identitária: “Um país que era o meu, que já tinha aprendido a estimar como qualquer outro catalão"10 (EL HACHMI, 2004, p.90).

A língua árabe é retratada como a língua dos opressores marroquinos em relação ao povo berbere e à língua amazigh. Com seu filho argumenta:

não é tão só a língua dos seus pais, é a língua dos opressores de um reino onde o amazigh sempre foi considerado de segunda categoria, língua oral, bárbara, dizem...a sua outra língua materna, o catalão, foi em outro tempo perseguida e menosprezada, não em vão sua mãe as sente como duas línguas irmãs. (EL HACHMI, 2004, p.27) ${ }^{11}$ 
Mesmo assim, mostra preocupação em que seu filho aprenda o amazigh, a língua de seus pais, como uma maneira de confirmar sua identidade híbrida:

Antes de você nascer, muito antes que tudo fosse concebido, o teu pai e eu tínhamos decidido que te falaríamos em amazigh... Não te dar a oportunidade de aprender a língua dos seus antepassados teria sido um crime contra a sua formação e contra os laços cada vez mais frágeis que te unem com o Marrocos. (EL HACHMI, 2004, p.20-21) ${ }^{12}$

12 No original: "Abans abans fins I tot que fossis concebut, el teu pare $\mathrm{i}$ jo tenien decidit que $\mathrm{t}^{\prime}$ haviem de parlar em amazic... No donar-te l'oportunitat d'aprendre la llengua dels teus avantpassats hauria sigut um crim contra la teva formació i contra els llaços cada vegada més febles que t'uneixem amb el Marroc."

13 No original: "I sent totes dues lengües marginades per certs poders, encara sentia mês el deure de defensar-les, d'elevar-les al lloc que els pertoca"

14 No original: "Espero que, com la teva mare, aprendàs a estimar-te totes les llenguës igual, patrimonio historic, 1legat més antic de totes les civilitzacions, músiques que ens arriben de molt lluny i que hem de preserver. Sabrás que no hi há idioma o dialecte millor ni pitjor, tots serveixen per expresser els nostres sentiments, els desigs i les frustracions."

15 No original: "se convierte en el elemento que ayuda a los personajes a cerrar los ciclos de aprendizaje, ya que al ordenar verbalmente todas las fases del proceso que experimentan consiguen entender la complejidad del entramado cultural en el que viven y afianzar su identidad como miembros de la comunidad multicultural a la que pertenecen".

16 No original: "escric per sentir-me més lliure, per desferme del meu propi enclaustrament, un enclaustrament fet de denominacions d'origen, de pors, d'esperances sovint entroncades, de dubtes continus"
Observamos essa dupla tensão: por um lado o árabe que oprime a língua amazigh e, por outro, a tentativa de opressão da língua catalã.

Por isso, sente-se como "defensora" de todas as línguas marginalizadas: "E sendo todas as duas línguas marginalizadas por certos poderes, sentia ainda mais o dever de defendê-las, de elevá-las ao lugar que elas pertencem"13 (EL HACHMI, 2004, p. 52). Sua identificação, entretanto, é com o catalão.

Finalmente, ainda com seu filho, El Hachmi reflete sobre a importância das línguas de um modo geral:

Espero que, com a tua mãe, aprenderás a estimar todas as línguas igualmente, patrimônio histórico, legado mais antigo de todas as civilizações, músicas que chegaram de muito longe e que temos de preservar. Saberás que não há idioma ou dialeto melhor nem pior, todos servem para expressar nossos sentimentos, desejos e frustrações (EL HACHMI, 2004, p.27). ${ }^{14}$

O texto de El Hachmi confirma, segundo Cristián Ricci, a função da literatura como veículo da identidade marroco-amazigh-catalã. A escrita literária

se converte em elemento que ajuda aos personagens a fechar os ciclos de aprendizagem, já que ao ordenar verbalmente todas as fases do processo que experimentam conseguem entender a complexidade do cruzamento cultural no qual vivem e afiançar sua identidade como membros da comunidade multicultural a qual pertencem ${ }^{15}$. (RICCI, 2008, p. 1)

Para El Hachmi a escrita da migração é uma escrita de negociação linguística e cultural, uma forma de empoderamento. Diz a autora:

escrevo para sentir-me mais livre, para me desfazer do meu próprio enclausuramento, um enclausuramento feito de denominações de origem, de medos, de esperanças constantemente truncadas, de dúvidas contínuas (EL HACHMI, 2004, p.14). ${ }^{16}$

Numa experiência comum a outros escritores, ela busca habitar multiterritorialidade linguística: tenta ser catalã sem ter que necessariamente abrir mão de toda a bagagem / herança que carrega.

Janet Paterson propõe que "um pensamento verdadeiramente migrante reconsidera o processo de semantização das di- 
ferenças, pois é incontestavelmente na diferença aceita, respeitada e não semantizada que reside a esperança de novas configurações e relações identitárias" (PATERSON, 2007, p.17). A noção de pertencer é desse modo questionada uma vez que "em alguns textos consagrados à escritura migrante, desenha-se um paradigma temático que reúne os seguintes topoi: o exílio, o sentimento de ser estrangeiro ("eu sou o outro"), o entre-dois (espacial, temporal e identitário), o no man's land e a melancolia" (PATERSON, 2007, p.18). Por isso a literatura da imigração reflete a função da imaginação criativa na produção fictícia de novo espaço identitário também na recreação da batalha para tentar sair desse não lugar.

Trata-se de uma reflexão sobre a função da produção de um novo espaço identitário híbrido, um modo de viver a multiterritorialidade, um modo de habitar várias línguas e tentar fazer desse novo espaço o seu verdadeiro lugar.

\begin{abstract}
The purpose of this paper is, through a reading of Jo també soc catalana (2004) by Najat El Hachmi, morroccan immigrant living in Barcelone, Spain, to think the ways in which the writer lives what Rogério Haesbaert calls multiterritorialityt. We will observe how through the experience of living various languages, Amazigh, Catalan, and Spanish, the writer reinforces the idea of a hybrid identity.
\end{abstract}

Key-words: multiterritory; hybrid identity; Najat El Hachmi.

\title{
REFERÊNCIAS
}

CELAYA-CARRILLO, Beatriz. "Pánico racistas: reflexiones sobre la inmigración em Cataluña y España a partir de um texto de Najat El Hachmi". MLN. The Johns Hopkins University Press, v. 126, p. 344-365, 2011.

EL HACHMI, Najat. Jo també soc catalana. Barcelona: Columna, 2004.

HAESBAERT, Rogério. O mito da desterritorialização: do "fim dos territórios" à multiterritorialidade. $3^{\mathrm{a}}$ ed. Rio de Janeiro: Bertrand Brasil, 2007.

MASSEY, Doreen. Space, place and gender. Minneapolis: University of Minnesota Press, 2009. MCDOWELL, Linda. Gender, identity and place: understanding feminist geographies. Minneapolis: University Minnesota Press, 2007. 
MIGNOLO, Walter. Histórias Locais / Projetos Globais. Colonialidade, saberes subalternos e pensamento liminar. Trad. Solange Ribeiro de Oliveira. Belo Horizonte: Editora UFMG, 2003.

NAÏR, Sami. La Europa Mestiza. Inmigración, ciudadanía, codesarrollo. Barcelona: Círculo de Lectores, S.A. / Galaxia Gutenberg, 2010.

PATERSON, Janet M. “Diferença e alteridade: questões de identidade e de ética no texto literário". In: Figurações da Alteridade. Org. FIGUEIREDO, Eurídice e PORTO, Maria Bernadette Velloso. Niterói, EdUFF, 2007.

RICCI, Cristián. "Najat El Hachmi y Laila Karrouch: escritoras marroquíes-imazighen calatanas em el marco del fenômeno migratorio moderno". marruecosdigital.net/xoops, 2008. Acesso em 25/06/2012.

SAYAD, Abdelmalek. A Imigração ou os paradoxos da alteridade. Trad. Cristina Muracho.São Paulo, EDUSP, 1998. 